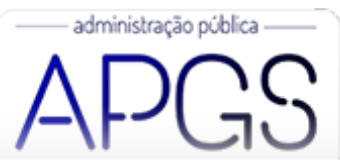

Administração Pública e Gestão Social ISSN: 2175-5787

apgs@ufv.br

Universidade Federal de Viçosa

Brasil

\title{
Governança e rating de crédito em municípios brasileiros
}

da Rosa Filho, Celso; Wagner da Fonseca, Marcos; Oliveira Soares, Rodrigo

Governança e rating de crédito em municípios brasileiros

Administração Pública e Gestão Social, vol. 12, núm. 3, 2020

Universidade Federal de Viçosa, Brasil

Disponible en: http://www.redalyc.org/articulo.oa?id=351563312013

Esta obra está bajo una Licencia Creative Commons Atribución-NoComercial-SinDerivar 3.0 Internacional. 


\section{Governança e rating de crédito em municípios brasileiros}

Governance and credit rating in Brazilian municipalities

Gobernanza y rating de crédito en municipios brasileños

Celso da Rosa Filho

Universidade Federal do Paraná, Brasil

Redalyc: http://www.redalyc.org/articulo.oa?

celsorosa@ufpr.br

Marcos Wagner da Fonseca

Universidade Federal do Paraná, Brasil

mwfonseca@ufpr.br

Rodrigo Oliveira Soares

Universidade Federal do Paraná, Brasil

rosoares@ufpr.br id $=351563312013$

Recepción: 20 Febrero 2019

Aprobación: 21 Septiembre 2019

Publicación: 01 Julio 2020

\section{Resumo:}

Neste artigo o objetivo é analisar a relação entre o índice de governança municipal, adotado pelo Conselho Federal de Administração (CFA) e a classificação do rating de crédito nos municípios brasileiros, calculada por meio da metodologia desenvolvida pela Secretaria do Tesouro Nacional (STN). A aplicação empírica utilizou a regressão ordinal múltipla para obter os resultados para análise. Dentre os resultados, cabe destacar que há influência positiva entre governança e classificação do rating de crédito nos municípios brasileiros. Quanto maior o escore de governança do município, melhor será a qualidade do crédito. Ademais, a pesquisa contribui para que gestores públicos atentem para as práticas adotadas de governança, uma vez que terão influência na obtenção de crédito presente e futuro, haja vista a relação com rating de crédito e, assim, os municípios terão capacidade de obter garantia da união e possibilitar maiores gastos em políticas públicas, criando um efeito multiplicador nos benefícios à população.

PalaVRas-CHAVE: Governança corporativa, governança pública, rating de crédito.

\section{Abstract:}

In this article, the objective is to analyze the relation between the municipal governance index adopted by the Federal Administration Council (CFA) and the classification of the credit rating in Brazilian municipalities, calculated using the methodology developed by the National Treasury Secretariat (STN). The empirical application used multiple ordinal regression to obtain the results for analysis. Among the results, it should be noted that there is a positive influence between governance and classification of credit rating in Brazilian municipalities. The higher the municipality's governance score, the better the credit quality. In addition, the research contributes to public managers to comply with the adopted governance practices, since they will influence present and future credit, given the relation with credit rating and thus, the municipalities will be able to obtain guarantee of the union and enable greater spending on public policies, creating a multiplier effect on benefits for the population.

KEYWORDS: Corporate governance, public governance, credit rating.

\section{ReSUMEN:}

En este artículo, el objetivo es analizar la relación entre el índice de gobernanza municipal, adoptado por el Consejo Federal de Administración (CFA) y la clasificación del rating de crédito en los municipios brasileños, calculada por medio de la metodología desarrollada por la Secretaría del Tesoro Nacional (STN). La aplicación empírica utilizó la regresión ordinal múltiple para obtener los resultados para el análisis. Entre los resultados, cabe destacar que hay influencia positiva entre gobernanza y clasificación del rating de crédito en los municipios brasileños. Cuanto mayor sea la puntuación de gobernanza del municipio, mejor será la calidad del crédito. Además, la investigación contribuye a que los administradores públicos cumplan con las prácticas de gobierno adoptadas, ya que influirán en el crédito presente y futuro, dada la relación con la calificación crediticia y, por lo 
tanto, los municipios podrán obtener la garantía del sindicato y permitir un mayor gasto en políticas públicas, creando un efecto multiplicador en los beneficios para la población.

Palabras clave: Gobierno corporativo, gobernanza pública, calificación creditícia.

\section{INTRODUÇÃO}

A partir da década de 1980, a governança iniciou seu desenvolvimento e passou a ser utilizada com significados distintos, impulsionando as construções teóricas provenientes do Banco Mundial, especificamente no ano de 1992, com o documento Governance and Development (Kjaer, 2004; MatiasPereira, 2010; Plattner, 2013). Desde então, observam-se várias compreensões, significados, usos, vertentes e perspectivas de governança. Para este artigo, aborda-se a compreensão da governança como uma administração de regras formais e informais quanto ao significado de uma atividade ou processo de controle, o uso como boa governança envolvendo um serviço público eficiente, seguindo a vertente administrativa sob a perspectiva racionalista. Neste sentido, Ezzamel e Reed (2008) destacam a importância da governança no sentido de monitoramento do conjunto de práticas (mecanismos de controle, monitoramento e de incentivos) que se esforçam para chegar a um acordo de complexidade, certeza e ambiguidade às organizações.

Nesse cenário, o controle e monitoramento das práticas de governança relacionam-se com a qualidade do crédito, de maneira a reduzir as externalidades negativas por meio da avaliação da capacidade de pagamento e vontade da entidade de honrar seus compromissos financeiros. A qualidade do crédito é mensurada pelas características da atual situação financeira e pelas expectativas de desempenho do devedor. Uma das ferramentas disponíveis para essa mensuração são os modelos de classificação de ratings de crédito (Murcia, 2012).

Nas organizações públicas, a governança pode ser entendida como o sistema que determina o equilíbrio de poder entre cidadãos, representantes eleitos, alta administração, gestores e colaboradores, com vistas a permitir que o bem comum prevaleça sobre os interesses das pessoas ou grupos (Matias-Pereira, 2010). O monitoramento das informaçóes, inerentes à governança, envolve o aspecto de produzir um serviço público eficiente, um sistema judicial independente e um quadro jurídico para executar contratos, seguindo uma administração equilibrada e responsável de fundos públicos, caracterizando-se o uso da governança como a boa governança (Leftwich, 1994). O objetivo do monitoramento compreende minimizar as incertezas frente à falha de mercado devido a informação assimétrica (moral hazard) (Hölmstrom, 1979), isto é, o monitoramento permite diminuir as perdas frente a incerteza ao orçamento e a capacidade de pagamento dos entes federativos. Dessa maneira, a Secretaria do Tesouro Nacional (STN) fez-se presente e tornou-se o órgão responsável por realizar o acompanhamento e averiguação das finanças dos entes subnacionais, a fim de evitar descontroles, assumindo o papel que antes era desempenhado pelo Senado (Torrezan, 2017). Desta forma, esse controle tem intuito de amenizar o conflito de agência.

Frente a esse contexto, buscaram-se estudos que tratam da relação entre governança e rating de crédito no âmbito da iniciativa privada, com publicações internacionais (Bhojraj \& Sengupta, 2003; Ashbaugh-Skaife, Collins, \& Lafond, 2006; Aman \& Nguyen, 2013) e nacionais (Silva, Santos, \& Almeida, 2012; Soares, Coutinho, \& Camargos, 2012; Pereira \& Martins, 2015). Porém, no Brasil não há estudos que tratem da relação entre governança e rating de crédito no setor público, o que abre espaço para a pesquisa apresentada neste artigo.

Desse modo, este artigo investiga a relação entre governança e classificação dorating de crédito no setor público. Diante do exposto, a questão de pesquisa que orienta o estudo é: Qual a relação entre governança e classificação do rating de crédito nos municípios brasileiros? Responder a esta questão é o objetivo principal deste estudo.

Justifica-se a elaboração da pesquisa inicialmente com o objetivo de contribuir com o arcabouço teórico e prático para o entendimento do efeito das práticas de governança sobre a classificação do rating de crédito 
aplicado ao setor público. Além disso, não há na literatura trabalhos sobre governança pública e classificação do rating de crédito aplicado ao setor público, mais especificamente em municípios brasileiros, tornando-se essencial para o entendimento da governança em contribuir com a capacidade de financiamento dos entes federativos. Ademais, o estudo é oportuno por estar inserido no processo de amadurecimento da Lei de Responsabilidade Fiscal (LRF) e contribui para as críticas às novas medidas propostas na metodologia de governança instituída pelo Conselho Federal de Administração (CFA) e na metodologia de classificação do rating de crédito desenvolvida pela Secretaria do Tesouro Nacional, ao mensurar a capacidade de financiamento dos entes federativos.

O presente artigo está estruturado da seguinte forma: Na próxima seção, será feita a revisão da literatura. Em seguida, procedimentos metodológicos. Depois, apresenta-se a descrição e análise dos resultados, segmentados por estatísticas descritivas, análise por agrupamento, associação entre as variáveis e influência da governança e a classificação do rating de crédito. Por fim, destacam-se as conclusões do artigo para evidenciar a relação do nível de influência da governança municipal e a classificação do rating de crédito.

\section{REVISÃO DA LITERATURA}

\subsection{Governança e Capacidade de se Financiar}

Etimologicamente, a palavra "governança" remonta o verbo grego kubernân ("pilotar" ou "dirigir"), que foi usado por Platão para descrever como desenhar um sistema de regras. Este termo grego tem a mesma conotação de "pilotos", "regras" ou "direção" (Kjaer, 2004; Plattner, 2013). O termo "governança” é sinônimo de "governo" e, segundo o dicionário Oxford, "governança" é "o ato ou a maneira de governar; o escritório ou função de governar". Governar é "dominar ou controlar com autoridade; estar no governo".

No entanto, durante a década de 1980, a palavra "governança" passou a ser utilizada com significados distintos de governo, a espelhar algo a mais, que vai além, a sustentar o impulso com as construções teóricas provenientes do Banco Mundial, especificamente no ano de 1992, com o documento Governance and Development (Kjaer, 2004; Matias-Pereira, 2010; Plattner, 2013).

Dessa forma, por mais que a distinção entre governo e governança tenha se firmado, o caráter polissêmico da governança é constante. Kjaer (2004) identifica três compreensões de governança: Auto-organização, governança global e governança como administração das regras formais e informais.

A primeira compreensão refere-se a "trabalhos de redes interorganizacionais caracterizados pela interdependência, troca de recursos, regras do jogo e autonomia significativa do estado" (Rhodes, 1997, p. 34); a segunda é concebida para incluir sistemas de regras em todos os níveis da atividade humana . da família à organização internacional . em que a busca por objetivos a partir do exercício do controle tem repercussões transnacionais; a terceira refere-se à administração das regras formais e informais do jogo.

A governança representa uma atividade ou processo de governo, uma condição da regra ordenada, pessoas encarregadas do dever de governar, método ou sistema pelo qual uma determinada sociedade é governada (Rhodes, 1996). Neste sentido, evidenciam-se pelo menos seis usos separados de governança: O Estado mínimo, governança corporativa, a nova gestão pública, boa governança, um sistema sócio cibernético e redes auto-organizadas (Rhodes, 1996).

Neste artigo, dentre os usos de governança, destaca-se a boa governança, a qual envolve um serviço público eficiente, um sistema judicial independente, responsável por fazer cumprir contratos, seguir uma administração responsável dos fundos públicos e responsável por uma legislatura representativa (Rhodes, 1996). Neste sentido, identificam-se três vertentes para a boa governança: Regras sistêmicas, políticas e administrativas. $\mathrm{O}$ uso sistêmico da governança é mais amplo do que o governo, cobrindo a distribuição de políticas econômicas, tanto internas quanto externas. $\mathrm{O}$ uso político da governança refere-se a um 
Estado desfrutar tanto de legitimidade quanto de autoridade, derivadas de um mandato democrático. $\mathrm{O}$ uso administrativo da governança refere-se a um serviço público eficiente e auditado que tenha competência burocrática para ajudar a projetar e implementar políticas adequadas que gerencie qualquer setor público (Leftwich, 1994).

A governança pode também ser representada por meio do conjunto de práticas e meios que se esforçam para chegar a um acordo com a complexidade, a certeza e a ambiguidade inerentes às organizações (Ezzamel $\&$ Reed, 2008). Neste sentido, a governança é uma arena complexa que levanta questões morais, políticas e científicas fundamentais sobre a direção da viagem que as sociedades estão seguindo (Ezzamel \& Reed, 2008). Esta complexidade da governança associa-se às perspectivas teóricas racionalistas e institucionalistas de maneira a explicar a especificação e o alcance de sua aplicação empírica.

A perspectiva racionalista destaca a intenção calculada e a maximização da eficiência, a perspectiva da governança prioriza o estudo das práticas organizadas por meio das quais se governa (Ezzamel \& Reed, 2008). Esta perspectiva investe na intenção humana que busca maximizar a realização de um conjunto predeterminado de objetivos, tipicamente na forma de lucros. A perspectiva institucionalista tenta alcançar uma síntese teórica seletiva por meio de duas abordagens, focalizando as necessidades de eficiência técnica e os imperativos de legitimidade que moldam a lógica institucional subjacentes às estruturas e práticas de governança (Ezzamel \& Reed, 2008). Kitagawa, Godoy, Albuquerque e Carvalho (2007), Berthelot, Morris e Morrill (2010) e Lee e Lin (2010) destacam que a governança se desenvolveu a partir da separação do controle da gestão nas empresas e está relacionada a um conjunto de práticas (mecanismos de controle, monitoramento e de incentivos). Nesse sentido, considera-se que o monitoramento das práticas de governança representa uma forma de controlar os gerentes para evitar perdas nas organizaçóes (Berthelot, Morris, \& Morrill, 2010).

Vale ressaltar que a governança aplicada ao setor público tem ampla discussão. Fukuyama (2013) conceitua governança como uma capacidade de criar e aplicar regras e de prestar serviços, independentemente se o governo é democrático ou não. No seu estudo, o autor da ênfase ao desenvolvimento da comunidade com o apoio mútuo da governança e da democracia. Neste sentido, o governo é uma organização que pode desempenhar melhor suas funções com auxílio da democracia. Pires e Gomide (2016) propõem avançar nessa discussão que afeta o desempenho e os resultados de políticas públicas até então observadas por meio de exame dos arranjos institucionais que marcaram a implementação de políticas públicas pelo governo federal no Brasil na última década. Os resultados contribuem para o avanço dos debates sobre a capacidade do Estado e suas decorrentes práticas de governança para o campo da gestão de políticas públicas.

Destacam-se os atores que fazem parte da cadeia de governança, abordados neste estudo

O controle e monitoramento das práticas de governança, por sua vez, relacionam-se com a qualidade do crédito, de maneira a reduzir as externalidades negativas por meio da avaliação da capacidade de pagamento e interesse da entidade de honrar seus compromissos financeiros (Murcia, 2012).

Sendo assim, a mensuração da capacidade de pagamento consiste no processo de quantificar a possibilidade de a instituição financeira incorrer em perdas, caso os fluxos de caixa esperados com as operações de crédito não se confirmem (Brito \& Assaf, 2008). Essa mensuração é feita a partir das características da atual situação financeira e das expectativas de desempenho do devedor. Uma das ferramentas disponíveis para essa mensuração são os modelos de classificação de ratings de crédito (Murcia, 2012). Na busca pela mensuração da capacidade da empresa de se financiar, a qualidade do risco pode ser um fator importante, de maneira a evidenciar o risco de a contraparte cumprir suas obrigações relativas (Bessis, 2011).

Para medir o rating no contexto brasileiro, destacam-se as agências de classificação Standard \& Poor's (S\&P), Austin Rating, Moody's e Fitch Ratings. Conforme o estudo de Brito e Pimentel (2012), as mais relevantes são Moody's, Standard \& Poor's e a Fitch Ratings. Essas agências emitem opiniões a partir de análises quantitativas e qualitativas, sobre o risco de inadimplência (Brito \& Pimentel, 2012). 
No que se refere à concepção da avaliação do risco relacionado ao crédito para as empresas ou rating de crédito, este pode ser um fator ligado à governança corporativa privada. Destacam-se a seguir estudos que apresentaram resultados semelhantes, os quais evidenciam uma relação positiva entre a governança e a classificação do rating de crédito, tendo utilizado, da mesma forma, a mesma metodologia de regressão aplicada em empresas privadas. No âmbito internacional destacam-se os estudos de Bhojraj e Sengupta (2003), Ashbaugh-Skaife, Collins e Lafond (2006) e Aman e Nguyen (2013) e no nacional, Silva, Santos e Almeida (2012), Soares, Coutinho e Camargos (2012) e Pereira e Martins (2015).

Bhojraj e Sengupta (2003) pontuam que nos Estados Unidos há uma relação entre governança corporativa e o rating em termos de rendimento de títulos, encontrando uma relação positiva entre as práticas de governança e as classificações dos títulos. Atingiram um total de 218 observações de empresas entre os anos de 1991 e 1996. Neste trabalho o modelo econométrico adotado foi o Probit ordenado e Regressão MQO. Como variável dependente foi utilizado o Rating em escala ordinal correspondendo a classificação da agência Moody's como variáveis independentes medidas de Governança Corporativa, Rendimentos e Classificações de títulos corporativos e como variáveis de controle as características da emissão das ações, como valor, prazo, valor contábil e de mercado, ativos totais, retorno e risco.

Ashbaugh-Skaife, Collins e Lafond (2006) tiveram como escopo pesquisar, no mercado norte-americano, se a adoção de boas práticas de governança corporativa poderia influenciar na classificação dos ratings de crédito e consideram que as características relacionadas às práticas de governança aumentam a probabilidade de as empresas receberem melhores classificações no rating. Atingiram um total de 280 observações de empresas para o ano de 2003. O modelo econométrico adotado foi o Logit ordenado. Como variável dependente foi utilizado o Rating em escala ordinal correspondendo a classificação da agência Standard \& Poor's, como variáveis independentes medidas de Governança Corporativa, Estrutura e processos, Direitos, Transparência e como variáveis de controle as características das empresas, como valor contábil e de mercado, tamanho, retorno.

Aman e Nguyen (2013) destacam, no mercado japonês, que as empresas com melhores classificações no índice de governança corporativa apresentaram melhores classificações no rating. Atingiram um total de 437 observações de empresas para o ano de 2003. Neste estudo o modelo econométrico adotado foi o Probit ordenado. Como variável dependente foi utilizado o Rating em escala ordinal correspondendo a classificação da R \& I, semelhante à agência Standard \& Poor's, como variáveis independentes medidas de Governança Corporativa disponível no Nikkei CGES (Sistema de Avaliação de Governança Corporativa), e como variáveis de controle as características das empresas, como valor de ativos, alavancagem, retorno e volatilidade.

No Brasil, Silva, Santos e Almeida (2012) afirmam que existe influência das práticas de governança corporativa no desempenho das debêntures classificadas por agências de rating. Neste estudo foi encontrada uma relação positiva para a concentração de propriedade, informando que pode influenciar de maneira significativa as classificações de rating. Para a proxy de governança corporativa apresentou uma relação contrária em relação ao desempenho das debêntures, ou seja, apresentou menor classificação no rating para as empresas com melhores indicadores de governança. Este estudo utilizou como modelo econométrico o Probit ordenado.

Soares, Coutinho e Camargos (2012) investigam os fatores determinantes das classificações dos ratings atribuídos pela agência Standard \& Poor's, encontram significância apenas nas variáveis relacionadas à governança corporativa. Por sua vez, Pereira e Martins (2015) analisam os efeitos das práticas de governança corporativa sobre o rating de crédito atribuído pela agência de classificação Moody's. Identificam uma relação positiva e significante do rating de crédito com os níveis de governança corporativa. Atingiram um total de 72 observações de empresas, entre os anos de 2009 a 2010. Neste trabalho o modelo econométrico adotado foi o Logit ordenado. O estudo utilizou como variável dependente a classificação do rating de crédito da Standard \& Poor's e como variável independente indicadores financeiros de rentabilidade, 
imobilização, endividamento e cobertura de juros, além das características das empresas como tamanho dos ativos, governança corporativa e abertura de capital.

Portando, percebe-se que, por meio dos achados evidenciados nos estudos apresentados anteriormente, as práticas da governança corporativa podem ser consideradas uma importante condição na determinação da capacidade de se financiar e, desta maneira, influenciar na classificação do rating de crédito.

Ademais, Rhodes (1996) destaca que a governança pode ser colocada no campo da administração da política pública, a qual não trata a governança como sinônimo de governo e sim como uma mudança no sentido do governo, mencionando a uma nova maneira de governar, uma circunstância alterada da regra pautada ou um novo mecanismo pelo qual a sociedade é governada.

A governança pública pode ser entendida como o sistema que determina o equilíbrio de poder entre os envolvidos - cidadãos, representantes eleitos (governantes), alta administração, gestores e colaboradores com vistas a permitir que o bem comum prevaleça sobre os interesses de pessoas ou grupos (Matias-Pereira, 2010).

Nas últimas décadas, os debates sobre Governança Aplicada ao Setor Público desenvolveram-se sob a égide da transparência e da responsabilidade de prestação de contas, como bases para assegurar um ambiente de maior proteção aos proprietários das empresas quanto ao alcance dos objetivos organizacionais (Cavalcante \& De Luca, 2013).

Especificamente no que se refere ao setor público, segundo o Tribunal de Contas da União (TCU) (2014), a crise fiscal dos anos 1980 exigiu novo arranjo econômico e político internacional, com a intenção de tornar o Estado mais eficiente. Assim, a governança no setor público pode ser mensurada por meio de um indicador conforme metodologia de cálculo instituída pelo Conselho Federal de Administração (CFA), Câmara de Gestão Pública (CGP), composto de três dimensões: Gastos e Finanças Públicas, Qualidade da Gestão e Desempenho (CFA, 2015).

Sobre essas dimensões provenientes da mensuração do Índice de Governança Municipal pode-se dizer que consistem no conjunto de boas práticas de gestão pública e que a boa governança é um requisito para países em desenvolvimento obterem recursos econômicos e apoios técnicos (Secchi, 2009). Dessa forma, a boa governança pode ser identificada por meio das dimensões propostas nesse índice e relacionada com a capacidade de se financiar e a classificação fiscal do município, associando a um rating de crédito.

$\mathrm{Na}$ abordagem do rating de crédito aplicado ao setor público, destaca-se o conceito da Secretaria do Tesouro Nacional, a forma de medir a capacidade de se financiar e a sua classificação de sua situação fiscal, associando um rating de crédito ao ente federativo analisado. Neste contexto, a Secretaria do Tesouro Nacional (2017), conceitua "rating" como sendo uma forma de verificar a capacidade de um ente se financiar, aferindo a possibilidade de captarem operações de crédito interna ou externa, associando ao respectivo ente federativo uma classificação de sua situação fiscal, ou seja, associando um rating ao ente em análise.

No setor público, as agências de classificações emitem opiniões sobre a qualidade do crédito dos governos nacionais e subnacionais. Essas classificações dos entes públicos funcionam como uma proxy do risco de inadimplência dos entes analisados, permitindo mensurar a predisposição e a capacidade de um ente se financiar para verificar a possibilidade de pagamento da dívida (Suzart, 2014).

A avaliação da capacidade de um ente (estados, Distrito Federal e municípios) se financiar é realizada por meio da portaria n 501 de 23 de novembro de 2017 da Secretaria do Tesouro Nacional (STN). Essa metodologia utiliza três indicadores (endividamento, poupança corrente e liquidez) para proceder a análise da capacidade de pagamento do ente federativo.

Desta forma, a análise da capacidade de um ente se financiar é pré-requisito para a concessão de aval para a contratação de operações de crédito internos e externos pelos estados, Distrito Federal e municípios. Cada indicador recebe uma nota de $\mathrm{A}$ a $\mathrm{C}$ para as faixas de valores assumidos e a combinação das três notas resulta na nota final do município, que pode ir de $\mathrm{A}$ a $\mathrm{D}$. Apenas a obtenção das notas A e B possibilitam a concessão da garantia da União para operação de crédito pleiteada. Portanto, a capacidade de financiamento de um 
ente federativo depende de decisões da Secretaria do Tesouro Nacional, uma vez que monitora por meio das regras para concessão de aval para realização de operações de crédito.

Diante desses conceitos, relacionados ao contexto da governança aplicada ao setor público e da capacidade de o ente federativo se financiar por meio da metodologia de classificação do rating de crédito, no âmbito da Administração Pública, espera-se encontrar uma relação de influência, corroborando com os achados no setor privado. Desta forma, para se fazer a verificação empírica da pesquisa, apresenta-se a seguinte hipótese: Há relação positiva entre a Governança e o rating de crédito dos municípios brasileiros.

\subsection{Governança, Accountabililty e Transparência}

Neste tópico busca-se, por meio da literatura nacional e internacional, aprofundar o entendimento da governança em relação aos temas como accountability e transparência aplicada ao setor público. Pereira (2009) buscou analisar a partir da literatura as motivações que levaram à adaptação e à transferência das experiências da Governança Corporativa para o setor público, argumentando que dentre as principais motivações estão às dificuldades que o Estado brasileiro tem para tornar eficazes as suas ações, que em geral são lentas e inflexíveis, refletindo na qualidade dos serviços públicos disponíveis à população. Retrata que a Governança Corporativa assume uma importância cada vez maior no que se refere às questóes que envolvem as relações complicadas que existem entre o Estado e o setor privado, constatando que o maior desafio a ser superado pelo governo brasileiro é a consolidação e institucionalização do processo de Governança Corporativa no país.

Outro estudo importante foi do Slomski (2010), que procurou discorrer sobre a demonstração do resultado econômico e sistemas de custeamento como instrumentos de evidenciação do cumprimento do princípio constitucional da eficiência, produção de governança e accountability no setor público. Esse trabalho utilizou a demonstração do resultado econômico e sistemas de custeamento como instrumentos de evidenciação do cumprimento do princípio constitucional da eficiência, produção de governança e accountability no setor público, uma aplicação na Procuradoria-Geral do Município de São Paulo.

A pesquisa de Cruz, Ferreira, Silva e Macedo (2012) buscaram verificar o nível de transparência das informações acerca da gestão pública divulgadas nos portais eletrônicos. Os autores verificaram a transparência da gestão pública municipal: Um estudo a partir dos portais eletrônicos dos maiores municípios brasileiros. Os resultados mostraram que a transparência da gestão pública municipal dos maiores municípios brasileiros é evidenciada nos sites do município. Outra pesquisa parecida com a anterior foi a de Bairral, Silva e Alves (2015), que analisaram o nível de transparência pública nos relatórios de gestão anuais de entidades públicas federais e os incentivos (político, institucional, governamental, social e financeiro) que podem afetar a divulgação da informação pública. Já os autores Bernardes, Santos e Rover (2015) analisam como a Lei de Acesso à Informação está sendo implementada pelas prefeituras da região Sul do país. Esse estudo trouxe um ranking das prefeituras da região Sul do Brasil, uma avaliação a partir de critérios estabelecidos na Lei de Acesso à Informação.

Viana (2010) busca identificar se os princípios de Governança Corporativa estão associados com evidências de melhoria nos resultados fiscais no setor público, associando a Governança Corporativa com a tomada de decisões gerenciais, desempenho, controle e também com a necessidade de prestação de contas para seus controladores. O autor salienta que o Brasil avançou com o marco regulatório da Lei de Responsabilidade Fiscal, que definiu para a gestão pública um rigor maior para o controle do desempenho econômico e mais transparência nas suas ações. O estudo salienta que o setor público deve buscar o aumento nos seus resultados, oferecendo maior retorno aos seus controladores, ou seja, a sociedade, adotando práticas e princípios de Governança Corporativa, pois tais princípios podem ser aplicados na gestão pública.

Pela análise dos estudos, percebe-se a importância de transferir as experiências da Governança Corporativa para a gestão pública, constatando que o Estado deve ter como um dos seus principais focos a busca do 
aperfeiçoamento de sua administração para atuar de forma eficaz e com transparência, visando atender as exigências da sociedade. Paralelamente, os estudos sobre governança no setor público receberam influência da abordagem da governança corporativa e estão relacionados à adoção de medidas para mensurar transparência, corrupção e ineficiência no uso dos recursos públicos. Cabe ressaltar que existem vários estudos sobre boas práticas de gestão no setor público elaboradas por órgãos internacionais como o International Federation of Accountants (IFAC), Organização para a Cooperação e Desenvolvimento Econômico (OCDE), TCU e Banco Mundial.

No âmbito internacional, destaca-se o estudo de Bolívar, Pérez e Hernández (2007), que examina o E-Governo e o Relatório Público financeiro dos governos regionais espanhóis. Os autores analisam se as organizações públicas estão tornando-se mais conscientes quanto à divulgação das informações financeiras em seus sites. Outro estudo que se destaca é o de Esmark (2009), que buscou a diferenciação funcional entre Governança e Governança Pública, para a além da hierarquia, de mercado e redes. Ele explora a relação entre a transformação atual da governança pública e da diferenciação funcional da sociedade.

Hwang e Akdede (2011) buscaram examinar se a qualidade da governança afeta a eficiência do setor público nas áreas de política de administração, educação, infraestrutura e estabilidade. Esse estudo retrata a influência do governo sobre a eficiência do setor público e teve a constatação de que as medidas de qualidade do governo de um país estão positivamente e significativamente associadas à eficiência do setor público nas áreas de política de administração, infraestrutura e estabilidade.

O estudo de Stewart, Asha e Shulman (2012) examinou as divulgações de governança corporativa nos sites do Estado australiano em departamentos governamentais e em relatórios anuais, que estão disponíveis para download. $O$ aspecto central recai sobre a natureza e extensão de informações sobre a governação e a facilidade de encontrar essas informações diretamente em sites de departamento e também em relatórios anuais, que estão disponíveis para download.

No estudo de Subramaniam, Stewart e Shulman (2013) foi realizada uma análise qualitativa de entrevistas semiestruturadas com 65 executivos e gerentes de nível médio de 25 departamentos em toda a Austrália. As entrevistas identificaram as percepções dos gerentes das estruturas e práticas de governança nas quatro áreas nomeadas: Planejamento estratégico, auditoria, gestão de risco e capacitação. $\mathrm{O}$ estudo acrescenta insights sobre os fatores comportamentais e organizacionais que incentivam ou impedem uma governação eficaz baseada nas experiências dos gerentes das funções chave da governança.

Aziz, Said e Alam (2015) avaliaram o status das práticas de prestação de contas do setor público da Malásia observando o relatório do auditor-geral que revelou corrupção, fraqueza e falta de controle no gerenciamento de ativos. Os resultados foram baseados na opinião dos entrevistados sobre 10 práticas de responsabilidade pública em seus respectivos departamentos ou agências usando a escala Likert de sete pontos de escala que variou de 1 (discordo totalmente) a 7 (concordo fortemente). A prestação de contas em serviços administrativos e diplomáticos, de educação, de médicos e de saúde encontra-se abaixo da média global. As conclusões do estudo são úteis na prestação de sensibilização aos formuladores de políticas e em ambientes de responsabilização encorajador em muitos países, especialmente a Malásia.

Pela análise dos estudos internacionais percebe-se a importância de se observar a qualidade das práticas de governança, pois pode afetar a eficiência do setor público nas áreas de política de administração, educação, infraestrutura e estabilidade. Estas informações podem ser divulgadas nos sites dos entes públicos e em relatórios anuais. Pode-se avaliar o status das práticas de prestação de contas do setor público com base em relatórios com vistas a revelar corrupção, fraqueza e falta de controle no gerenciamento de ativos públicos. Uma forma de analisar tais práticas é por meio do uso da escala Likert.

Cabe ressaltar que podem existir outros estudos sobre governança aplicada ao setor público e que não foram tratados neste trabalho. Contudo, espera-se que a revisão apresentada atinja o objetivo de suportar a análise dos resultados deste trabalho. 


\section{PROCEDIMENTOS METODOLÓGICOS}

Este estudo, quanto à abordagem metodológica, classifica-se como empírico e, em relação ao problema, como quantitativo. Do ponto de vista dos objetivos, caracteriza-se como descritivo.

\subsection{População e composição da amostra}

A população da pesquisa foi composta por 5.570 municípios do Brasil, conforme último levantamento do Instituto Brasileiro de Geografia e Estatística (IBGE) (2010), totalizando uma amostra de 669 municípios, seguindo o critério de disponibilidade de informações para mapear o Índice de Governança Municipal, instituído pelo Conselho Federal de Administração, e para calcular os indicadores que compõem a classificação do rating de crédito municipal, conforme metodologia proposta pela STN. Após este levantamento, a composição da amostra ficou assim representada, para o ano de 2015:

- Municípios de até 20.000 habitantes - 225, representando 33,63\%;

- Municípios de 20.001 a 50.000 habitantes, 153 (22,87\%);

- Municípios de 50.001 a 100.000 habitantes, 137;

- Municípios acima de 100.001 habitantes, 154 (23,02\%).

Percebe-se uma amostra representativa em todos os portes. Em relação ao processo de análise dos dados, foi utilizado o agrupamento por porte, respeitando as semelhanças e diferenças dentro de cada grupo.

\subsection{Coleta de dados}

O processo de coleta de dados ocorreu da seguinte maneira: Primeiramente foi realizado uma procura em bases de dados (Portal de Periódicos Coordenação de Aperfeiçoamento de Pessoal de Nível Superior [CAPES], Scopus, Science Direct e Spell), com as palavras chaves "Corporate Governance", "Credit Rating” e "Public Governance", para verificar os artigos relacionados com a temática. Posteriormente foi obtido no site do Conselho Federal de Administração os índices de governança municipal, limitados para o ano de 2015.

Diante desta limitação, procedeu-se o seguinte roteiro para identificar as informações necessária para tabular e calcular o rating de crédito municipal:

- Coleta das variáveis junto a base de dados do Finanças do Brasil (FINBRA) e Sistema de Informações Contábeis e Fiscais do Setor Público (SICONFI), mais especificamente nos Demonstrativos das Contas Anuais (DCAs), no período de 2012 a 2014, devido ao fato de o cálculo das variáveis do indicador de poupança corrente ser feito por meio da média aritmética dos últimos 3 anos, e no Relatório de Gestão Fiscal (RGF) no período de 2015 (para o cálculo dos indicadores de endividamento e liquidez);

- Cálculo dos indicadores que compõem a classificação do rating de crédito municipal, conforme a metodologia proposta pela STN, e foi verificado se existia o índice de governança do respectivo município.

Para obtenção dos dados das variáveis de controle, capital e porte, a fonte utilizada foi o site do IBGE. Para as variáveis referentes ao Fundo de Participação Municipal e as Operações de Crédito, foram coletadas junto à base de dados do FINBRA e SICONFI, também para o ano de 2015.

\subsection{Variáveis e equação do modelo da pesquisa}

Considerando a questão de pesquisa "Qual a relação entre governança e classificação do rating de crédito nos municípios brasileiros?”, este estudo foi operacionalizado de modo a relacionar as variáveis de Governança 
Municipal - IGM (CFA) e o Rating de Crédito Aplicado ao Setor Público, evidenciando assim os elementos que farão parte da estrutura metodológica deste processo, conforme ilustrado de forma sintética na Tabela 1.

Tabela 1 . Identificação das Variáveis e Referências

\begin{tabular}{|c|c|c|c|}
\hline \multicolumn{4}{|l|}{ Identificação das Variáveis } \\
\hline \multicolumn{2}{|l|}{ Independente (X) } & \multirow{2}{*}{\multicolumn{2}{|c|}{ Dependente (Y) }} \\
\hline \multirow{4}{*}{ Governança Municipal Valor do escore atribuído ao Município da Amostra 2015} & Dimensões & & \\
\hline & Gastos e Finanças Públicas & \multirow{3}{*}{$\begin{array}{l}\text { Rating } \\
\text { Classificação } \\
\text { atribuida ao } \\
\text { Município da } \\
\text { Amostra } 2015\end{array}$} & $\begin{array}{l}\text { Indicador de } \\
\text { Endividamento Faixa de } \\
\text { Solvência }\end{array}$ \\
\hline & Qualidade da Gestão & & $\begin{array}{l}\text { Indicador de Poupança } \\
\text { Faixa de aumento de } \\
\text { Poupanca }\end{array}$ \\
\hline & Desempenho & & $\begin{array}{l}\text { Indicador de Liquidez } \\
\text { Faixa de Capacidade de } \\
\text { Pagamento }\end{array}$ \\
\hline Referências & CFA (2015) & Referências & $\operatorname{STN}(2017)$ \\
\hline
\end{tabular}

Fonte: Elaborado pelo autor (2018).

Além das variáveis destacadas acima, utilizou-se no trabalho variáveis de controle com a finalidade de auxiliar a análise da relação entre a Governança Municipal e a Classificação do Rating de Crédito Aplicado ao Setor Público. As variáveis Capital (CAP), Operações de Crédito (OPCR), Fundo de Participação Municipal (FPM) e Porte (PORT) foram consideradas neste trabalho por apresentarem potencial explicativo para a relação previamente estabelecida, evidenciadas na Tabela 2.

Tabela 2 . Identificação das Variáveis de Controle

\begin{tabular}{|l|l|l|l|}
\hline Variáveis & $\begin{array}{l}\text { Definição } \\
\text { Constitutiva }\end{array}$ & Definição Operacional & Referências \\
\hline CAP & Dummy & $\begin{array}{l}\text { Variável que assume o } \\
\text { valor "1" para capitaise } \\
\text { "O" para não capitais. }\end{array}$ & IBGE (2010) \\
\hline OPCR & Dummy & $\begin{array}{l}\text { Variável que assume o } \\
\text { valor "1" para os } \\
\text { municipios que fazem } \\
\text { operações de crédito e } \\
\text { "O" para os que não } \\
\text { fazem. }\end{array}$ & SICONFI (2018) e FINBRA (2018) \\
\hline FPM & Dummy & $\begin{array}{l}\text { Variável que assume o } \\
\text { valor "1" para os } \\
\text { municipios que recebem } \\
\text { recursos e "0" para os } \\
\text { que não recebem. }\end{array}$ & SICONFI (2018) e FINBRA (2018) \\
\hline PORT & Dummy & Dummy respectivo porte. & IBGE (2010) \\
\hline
\end{tabular}

Fonte: Elaborado pelo autor (2018).

O formato da equação para este modelo da pesquisa, conforme sugerido por Favero (2009), busca testar se a governança pode ser considerada fator explicativo para a capacidade de o ente federativo de se financiar, por meio das notas atribuídas na classificação de rating de crédito proposta pela metodologia da Secretaria do Tesouro Nacional. Avalia-se também os efeitos da governança municipal e das variáveis de controle em relação às classificações de rating de crédito. O modelo é apresentado na Equação 1, abaixo. 
$R A T_{i}=\beta_{0}+\beta_{1} G O V_{i}+\beta_{2} C A P_{i}+\beta_{3} O P C R_{i}+\beta_{4} F P M_{i}+\beta_{5} P O R T_{i}+\varepsilon_{i}$

Em que:
$R A T_{i}=$ Rating de Crédito do município $i$;

$G O V_{i}=$ Índice de Governança do município $i$;

$C A P_{i}=$ Variável dummy que assume o valor "1" caso o município $i$ represente uma capital e

" 0 " para o contrário;

$O P C R_{i}=$ Variável dummy que assume o valor "1" caso o município $i$ tenha realizado

operações de crédito e " 0 " para o contrário;

$F P M_{i}=$ Variável dummy que assume o valor "1" caso o município $i$ receba recurso do fundo

de participação municipal e "0" para o contrário;

$P O R T_{i}=$ Variáveis dummy para cada classificação por porte do município $i$;

$\beta_{0}, \beta_{1}, \beta_{2}, \beta_{3}, \beta_{4}, \beta_{5}=$ Coefícientes do modelo de regressão;

$\varepsilon_{i}=$ Erro da regressão do município $i$.

A escolha da Regressão Ordinal Múltipla, decorre em função de a variável dependente ser composta pelas notas de classificação de rating de crédito, mensuradas em escala nominal ou ordinal (Favero, 2009).

\subsection{Tratamento de dados e aplicação do modelo}

Para a análise dos dados, utilizaram-se os softwares Excel $2013^{\circ}$ para a tabulação e cálculo dos indicadores e o SPSS $^{\oplus}$ v. 21 para a estatística descritiva, correlação entre as variáveis e por meio da metodologia da Regressão Ordinal Múltipla, o processamento da influência das variáveis, a fim de verificar as informações de ajuste do modelo, o poder explicativo e as estimativas do parâmetro.

\section{DESCRIÇÃO E ANÁLISE DE RESULTADOS}

\subsection{Estatísticas descritivas}

A Tabela 3 apresenta a estatística descritiva das variáveis de teste que formam o escore de governança dos municípios brasileiros. Ressalta-se que para os municípios da amostra foram observados os dados referentes ao período de 2015, reunindo um total de 669 municípios.

Tabela 3 . Estatística descritiva das variáveis de Governança Municipal

\begin{tabular}{lcccccc}
\hline Variáveis & Obs. & Mínimo & Máximo & Média & $\begin{array}{l}\text { Desvio } \\
\text { Padrão }\end{array}$ & $\begin{array}{l}\text { Coeficiente } \\
\text { de Variação } \\
\text { \% }\end{array}$ \\
\hline Governança Municipal & $\mathbf{6 6 9}$ & $\mathbf{0 , 2 9 7 7}$ & $\mathbf{0 , 7 6 6 6}$ & $\mathbf{0 , 5 2 2 0}$ & $\mathbf{0 , 0 9 0 9}$ & $\mathbf{1 7 , 4 2 \%}$ \\
Gastos e Finanças Públicas & 669 & 0,0902 & 0,9042 & 0,3612 & 0,1139 & $31,55 \%$ \\
Qualidade da Gestão & 669 & 0,2646 & 0,8987 & 0,5979 & 0,1121 & $18,76 \%$
\end{tabular}

Fonte: Dados da pesquisa (2018).

Pode-se visualizar na Tabela 3 que a variável do escore de governança municipal apresenta baixa dispersão, uma vez que o coeficiente de variação foi de $17,42 \%$, o que indica que os dados não se afastam da média e apresentando valores abaixo de 30\%, o conjunto poderá ser considerado homogêneo (Favero, 2009). Da mesma forma, considera-se com baixa variabilidade as variáveis que formam o escore de governança municipal. Portanto, pode-se afirmam que o conjunto das variáveis não apresentam outliers. 
Por sua vez, a capacidade do ente federativo de se financiar é demonstrada nas classificações das notas de rating de crédito, as quais representam a qualidade do crédito dos municípios por meio de classificações qualitativas, ou seja, as notas atribuídas são compostas por letras.

Neste estudo foram atribuídos valores às classificações de rating de crédito por meio de escala ordinal, destinando 4 para os municípios com classificações dos ratings de crédito municipal com a nota A; 3 para os municípios com classificações dos ratings de crédito municipal com a nota B; 2 municípios com classificações dos ratings de crédito municipal com a nota $\mathrm{C}$ e 1 municípios com classificações dos ratings de crédito municipal com a nota D. Dessa forma, os municípios tiveram sua categorização de $\mathrm{A}$ a $\mathrm{D}$, sendo que se o respectivo município for classificado com a nota $\mathrm{A}$ ou $\mathrm{B}$, terá aval da União para operaçóes de crédito interno ou externo. Caso contrário, não, de acordo com os critérios descritos na metodologia do STN.

A seguir são descritos os dados que evidenciam os resultados das variáveis referentes aos índices que formam a capacidade do ente federativo de se financiar, por meio da classificação do rating de crédito, representando a realidade dos municípios pesquisados para o ano de 2015 . O propósito é inferir sobre as principais medidas de dispersão das variáveis, que compõem a amostra rating de crédito municipal.

Tabela 4 . Estatística descritiva das variáveis do rating de crédito municipal

\begin{tabular}{lllllll}
\hline Variáveis & Obs. & Mínimo & Máximo & Média & $\begin{array}{l}\text { Desvio } \\
\text { Padrão }\end{array}$ & $\begin{array}{l}\text { Coeficiente } \\
\text { de Variação }\end{array}$ \\
\hline Rating Municipal & 669 & $\mathbf{2}$ & $\mathbf{4}$ & $\mathbf{3 , 4 1 1 0}$ & $\mathbf{0 , 8 2 0 7}$ & $\mathbf{2 4 , 0 6 \%}$ \\
Endividamento & 669 & $-0,0514$ & 2,2154 & 0,2193 & 0,2514 & $114,63 \%$ \\
Poupança & 669 & 0,5561 & 2,2735 & 0,8638 & 0,1227 & $14,21 \%$ \\
Liquidez & 669 & $-238,0320116,7202$ & 0,8167 & 11,8813 & $1454,63 \%$ \\
\hline
\end{tabular}

Fonte: Dados da pesquisa (2018).

$\mathrm{Na}$ Tabela 4, visualiza-se uma alta dispersão nos indicadores de endividamento e liquidez, porém, considerando que os dados destas variáveis não interferem no resultado final da nota de classificação do rating de crédito, conforme a metodologia adotada, não há necessidade de tratamento de outliers.

\subsection{Análise por agrupamento}

Após análise descritiva geral dos municípios que compõem a amostra, foram agrupados os municípios, por porte, respeitando as semelhanças e diferenças dentro de cada grupo. A Tabela 5 apresenta os resultados obtidos das médias das variáveis relacionadas, considerando o agrupamento por porte.

Tabela 5. Municípios com média de Rating e Índice de Governança Municipal por agrupamento

\begin{tabular}{|c|c|c|c|}
\hline Porte dos Municípios & Habitantes & Rating & $\begin{array}{l}\text { Índice de } \\
\text { Governança } \\
\text { Municipal } \\
\end{array}$ \\
\hline $\begin{array}{l}\text { Pequeno Porte } 1 \text { (até } \\
20.000 \text { habitantes) }\end{array}$ & 225 & 3,4464 & 0,4789 \\
\hline $\begin{array}{l}\text { Pequeno Porte } 2 \\
\text { (20.001 a } 50.000 \\
\text { habitantes) }\end{array}$ & 153 & 3,2418 & 0,4915 \\
\hline $\begin{array}{l}\text { Média Porte (50.001 a } \\
100.000 \text { habitantes) }\end{array}$ & 137 & 3,3941 & 0,5396 \\
\hline $\begin{array}{l}\text { Grande Porte (Mais de } \\
100.001 \text { habitantes) }\end{array}$ & 154 & 3,5519 & 0,5994 \\
\hline Total & 669 & & \\
\hline
\end{tabular}


Fonte: Dados da pesquisa (2018).

Percebe-se por meio do agrupamento utilizado que as médias das variáveis tendem a apresentar um melhor índice de governança à medida que aumenta a quantidade de habitantes, da mesma forma que ocorre com as notas de classificação do rating de crédito. Estes resultados apontam que os municípios semelhantes, em questão de número de habitantes, têm uma classificação própria da capacidade de se financiar e observase um aumento no índice de governança, podendo significar uma melhor estrutura de governança para os municípios de maior porte.

A seguir é descrita a amplitude do escore de governança, considerando o porte dos municípios, representando a realidade dos municípios pesquisados para o ano de 2015 . O propósito é inferir sobre a dispersão da variável por agrupamento.

Tabela 6. Amplitude do escore de governança municipal por agrupamento

\begin{tabular}{|c|c|c|c|c|c|}
\hline Porte dos Municípios & Obs. & Mínimo & Máximo & Média & Amplitude \\
\hline $\begin{array}{l}\text { Pequeno Porte } 1 \text { (até } 20.000 \\
\text { habitantes) }\end{array}$ & 225 & 0,4655 & 0,6519 & 0,4790 & 0,1864 \\
\hline $\begin{array}{l}\text { Pequeno Porte } 2 \text { ( } 20.001 \mathrm{a} \\
50.000 \text { habitantes) }\end{array}$ & 153 & 0,5306 & 0,7666 & 0,4915 & 0,2360 \\
\hline $\begin{array}{l}\text { Média Porte (50.001 a } 100.000 \\
\text { habitantes) }\end{array}$ & 137 & 0,4205 & 0,6212 & 0,5396 & 0,2006 \\
\hline $\begin{array}{l}\text { Grande Porte (Mais de } 100.001 \\
\text { habitantes) }\end{array}$ & 154 & 0,2977 & 0,6108 & 0,5995 & 0,3131 \\
\hline
\end{tabular}

Fonte: Dados da pesquisa (2018).

$\mathrm{Na}$ Tabela 6, visualiza-se uma baixa dispersão nos três primeiros agrupamentos. Já nos municípios de grande porte, observa-se uma maior variabilidade no escore de governança, encontra-se municípios com piores resultados para o índice e os melhores resultado são encontrados nos municípios de pequeno porte 2. Desta forma, podemos afirmar que existem alguns municípios com grande quantidade de habitantes, porém, com baixo resultado nas dimensões que formam o índice de governança.

Em seguida, realizou-se a correlação de Spearman devido a não normalidade dos dados, conforme apresentado na Tabela 7.

\subsection{Associação entre as variáveis}

A Tabela 7 apresenta os resultados obtidos nas variáveis utilizadas, que compõem as métricas utilizadas para mensurar o escore de governança e a capacidade do ente federativo de se financiar, por meio das notas de classificação do rating de crédito.

Tabela 7 . Matriz de correlação das variáveis da pesquisa

\begin{tabular}{|c|c|c|c|c|c|c|}
\hline & & Rating & $\begin{array}{l}\text { Gastos e Finanças } \\
\text { Públicas }\end{array}$ & Qualidade da Gestão & Desempenho & $\begin{array}{l}\text { Índice de Governança } \\
\text { Municipal }\end{array}$ \\
\hline Rating & $\begin{array}{l}\text { Coeficiente } \\
\text { Significante }\end{array}$ & 1 & & & & \\
\hline Gastos e Finanças Públicas & $\begin{array}{l}\text { Coeficiente } \\
\text { Significante }\end{array}$ & $\begin{array}{l}0,326^{* * *} \\
0,000\end{array}$ & 1 & & & \\
\hline Qualidade da Gestão & $\begin{array}{l}\text { Coeficiente } \\
\text { Significante }\end{array}$ & $\begin{array}{l}0,198^{* * *} \\
0,000\end{array}$ & $\begin{array}{l}0,275^{* * *} \\
0,000\end{array}$ & 1 & & \\
\hline Desempenho & $\begin{array}{l}\text { Coeficiente } \\
\text { Significante }\end{array}$ & $\begin{array}{l}0,266^{* * *} \\
0,000\end{array}$ & $\begin{array}{l}0,550^{* * *} \\
0,000\end{array}$ & $\begin{array}{l}0,438^{* * *} \\
0,000\end{array}$ & 1 & \\
\hline $\begin{array}{l}\text { Indice de Governança } \\
\text { Municipal }\end{array}$ & $\begin{array}{l}\text { Coeficiente } \\
\text { Significante }\end{array}$ & $0,336 * * * 0,000$ & $0,760 * * * 0,000$ & $0,711 * * * 0,000$ & $0,852^{* * *} 0,000$ & 1 \\
\hline
\end{tabular}


${ }^{* * *}$ significante ao nível de $1 \%$ ** significante ao nível de 5\%* significante ao nível de $10 \%$

Nota. Fonte: Dados da pesquisa (2018).

*** significante ao nível de $1 \%,{ }^{* *}$ significante ao nível de $5 \%,{ }^{*}$ significante ao nível de $10 \%$.

A Tabela 7 revela que todas as dimensões que formam o Índice de Governança Municipal são significativas ao nível de $1 \%$ e a correlação observada no conjunto é de 33,6\%. Este resultado aponta que os municípios que têm melhores resultados em todas as dimensões podem apresentar melhor capacidade de se financiar.

\subsection{Influência da Governança e a Classificação do Rating de Crédito}

Quanto à identificação da influência entre a governança municipal e a classificação do rating de crédito, utilizou-se a regressão ordinal múltipla, a qual permite que a variável categórica dependente apresente mais de duas categorias, as quais, por sua vez, podem ser de natureza nominal ou ordinal (Favero, 2009).

O primeiro passo analisado é a significância do modelo, que foi realizada por meio do teste Qui-Quadrado, sob a hipótese nula de que o coeficiente é igual a zero, sendo calculada pelo quadrado da razão entre o coeficiente e o seu erro padrão (Favero, 2009). Esse teste é semelhante ao teste t aplicado aos modelos lineares. A Tabela 6 mostra o resultado da aplicação desse teste no modelo desenvolvido, o qual teve estatística QuiQuadrado de 112,772, com significância de 0,000, o que leva à rejeição da hipótese nula e à interpretação de que os coeficientes do modelo são estatisticamente diferentes de zero.

Ademais, para determinar quão bem o modelo se ajusta aos dados, examinou-se o log-verossimilhança. Dessa maneira, os valores maiores do log-verossimilhança indicam um melhor ajuste aos dados (Gujarati, 2006; Favero, 2009). Na Tabela 8, evidencia-se o resultado indicando um alto valor de log-verossimilhança, portanto, o modelo se ajusta aos dados da amostra.

Tabela 8 . Informações de ajuste do modelo

\begin{tabular}{llll}
\hline Modelo & $\begin{array}{l}\text { Verossimilhança de log Qui-quadrado } \\
-2\end{array}$ & $\begin{array}{l}\text { Graus de liberdade } \\
\text { (df) }\end{array}$ & Sig. \\
\hline $\begin{array}{l}\text { Apenas } \\
\text { interceptação }\end{array}$ & 1225,048 & & \\
& & &
\end{tabular}

Fonte: Dados da pesquisa (2018).

Fonte: Dados da pesquisa (2018).

Função de ligação: Logit.

${ }^{* * *}$ significante ao nível de $1 \%,{ }^{* *}$ significante ao nível de $5 \%$ e ${ }^{*}$ significante ao nível de $10 \%$.

A avaliação do poder explicativo do modelo é analisada pelos coeficientes Pseudo $R^{2}$, que indicam quanto da variação da variável de interesse é capturada pelo modelo (Favero, 2009). O Pseudo $R^{2}$ de Cox e Snell $R^{2}$, Nagelkerke $\mathrm{R}^{2}$ e o McFadden $\mathrm{R}^{2}$ são medidas que se assemelham ao coeficiente de determinação da regressão linear (Gujarati, 2006). Maiores valores dessas medidas indicam maior explicação do modelo. A Tabela 9 apresenta os valores do Pseudo $\mathrm{R}^{2}$ de Cox e Snell $\mathrm{R}^{2}$, Nagelkerke $\mathrm{R}^{2}$ e o McFadden $\mathrm{R}^{2}$ do modelo.

Tabela 9 . Informações do Pseudo R quadrado

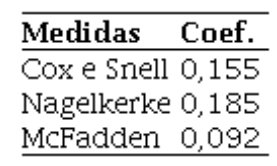

Fonte: Dados da pesquisa (2018). Função de ligação: Logit. 
${ }^{* * *}$ significante ao nível de $1 \%{ }^{* *}$ significante ao nível de $5 \% \mathrm{e}^{*}$ significante ao nível de $10 \%$

A análise da significância estatísticas de cada coeficiente é feita com base no teste Wald. Os resultados do teste Wald para o modelo proposto indicam que os parâmetros das três variáveis independentes selecionadas são estatisticamente diferentes de zero (Gujarati, 2006). A Tabela 10 apresenta as estimativas dos parâmetros das variáveis do modelo, bem como o modelo padrão, as estatísticas Wald, os graus de liberdade e os valores das probabilidades.

Tabela 10 . Estimativas do parâmetro do modelo

\begin{tabular}{|c|c|c|c|c|c|}
\hline Variável & Estimativas & $\begin{array}{l}\text { Modelo } \\
\text { padrão }\end{array}$ & Teste Wald & $\begin{array}{l}\text { Graus de } \\
\text { liberdade (df) }\end{array}$ & Sig. \\
\hline$\overline{\mathrm{GOV}}$ & 10,184 & 1,234 & 68,070 & 1 & $0,000^{* * *}$ \\
\hline $\mathrm{CAP}=0$ & 1,484 & 0,463 & 10,276 & 1 & $0,001^{* * *}$ \\
\hline$C A P=1$ & $0^{\mathrm{a}}$ & & & 0 & \\
\hline $\mathrm{PORT}=1$ & 0,889 & 0,297 & 8,943 & 1 & $0,003^{* * *}$ \\
\hline $\mathrm{PORT}=2$ & 0,209 & 0,296 & 0,498 & 1 & 0,481 \\
\hline $\mathrm{PORT}=3$ & 0,056 & 0,284 & 0,039 & 1 & 0,843 \\
\hline $\mathrm{PORT}=4$ & $\mathrm{O}^{\mathrm{a}}$ & & & 0 & \\
\hline $\mathrm{FPM}=0$ & $-0,590$ & 0,545 & 1,173 & 1 & 0,279 \\
\hline $\mathrm{FPM}=1$ & $0^{\mathrm{a}}$ & & & 0 & \\
\hline $\mathrm{OPCR}=0$ & $-0,220$ & 0,240 & 0,838 & 1 & 0,360 \\
\hline $\mathrm{OPCR}=1$ & $0^{\mathrm{a}}$ & & & 0 & \\
\hline
\end{tabular}

Fonte: Dados da pesquisa (2018).

Função de ligação: Logit.

a. Este parâmetro é definido para zero porque é redundante.

${ }^{* * *}$ significante ao nível de $1 \%,{ }^{* *}$ significante ao nível de $5 \%$ e* significante ao nível de $10 \%$.

Com base na Tabela 10, o coeficiente da variável explicativa governança se mostrou significativa, ao nível de $1 \%$. Apresentou p-valor de 0,000, rejeitando-se a hipótese nula de que a regressão não é significativa.

Neste contexto, existe uma relação significativa e positiva entre a governança municipal e a classificação de rating de crédito. Desta forma, o conjunto de boas práticas de gestão pública exerce influência positiva sobre a qualidade do crédito municipal, que se traduz pela capacidade de o município se financiar.

Portanto, verifica-se que esta relação atendeu à relação esperada, como evidenciado nos estudos internacionais (Bhojraj \& Sengupta, 2003; Ashbaugh-Skaife, Collins, \& Lafond, 2006; Aman \& Nguyen, 2013) e no âmbito nacional (Silva, Santos, \& Almeida, 2012; Soares, Coutinho, \& Camargos, 2012; Pereira \& Martins, 2015), que buscaram a relação entre a Governança e o Rating de Crédito, no setor privado.

A variável capital apresentou significância estatística, ou seja, o município sendo capital de um estado da federação tende a apresentar maiores classificações do rating de crédito. Neste sentido, ao apresentar uma estimativa positiva, indica que quanto maior a governança entre as capitais, melhor será a classificação do rating de crédito.

Percebe-se por meio do agrupamento utilizado, que as médias das variáveis tendem a apresentar um melhor índice de governança à medida que aumenta a quantidade de habitantes, da mesma forma ocorre com as notas de classificação do rating de crédito. Estes resultados apontam que os municípios semelhantes, em questão de número de habitantes, têm uma classificação própria da capacidade de se financiar, pois os municípios maiores tendem a possuir um sistema mais complexo de governança, no sentido das articulações do aparato burocrático, tributário e orçamentário.

Em relação às variáveis de agrupamento por porte, observa-se uma significância estatística nos municípios de até 20.000 habitantes (Pequeno Porte 1). Observou-se que este porte apresenta uma associação de que, quanto maior o nível de governança, melhor a classificação do rating de crédito do município. Os resultados das demais classificações não estão associados à relação das variáveis. Porém, nota-se uma classificação própria 
da capacidade de se financiar e um aumento no índice de governança, à medida que a quantidade de habitantes aumenta, podendo significar uma melhor estrutura de governança para os municípios de maior porte.

As variáveis de fundo de participação municipal e operações de crédito não apresentaram significância estatística. Dessa forma, o recebimento de recursos da União e dos Estados e a realização de operações de crédito não interferem na associação entre Índice de Governança Municipal e as notas de classificação do rating de crédito.

Como teste de robustez, segregou-se o resultado do escore de governança municipal em quartis, o que permitiu inferir se o resultado encontrado na relação se mantém, considerando níveis altos e baixos de governança. Na Tabela 11, apresenta-se cada quartil, os quais são compostos por 167 observações cada.

Tabela 11 . Identificação dos níveis de Governança Municipal

\begin{tabular}{lllll}
\hline \multirow{2}{*}{ Quartis } & \multicolumn{2}{l}{ Parâmetro (GOV) } & \multirow{2}{*}{$N^{\circ}$ Obs. } & \multirow{2}{*}{ Níveis } \\
\cline { 2 - 5 } & De & Até & & \\
\hline Q1 & 0,2977 & 0,4489 & 167 & Péssima \\
\hline Q2 & 0,4497 & 0,5279 & 167 & Baixa \\
\hline Q3 & 0,5281 & 0,5936 & 167 & Boa \\
\hline Q4 & 0,5937 & 0,7666 & 168 & Alta \\
\hline
\end{tabular}

Fonte: Elaborado pelo autor com base nos dados disponíveis (2018).

Os valores apresentados nesta tabela representam um escore de governança que assume valores entre

0,2977 e 0,7666. Estes valores se referem aos níveis péssima, baixa, boa e alta governança, respectivamente.

Os escores de governança municipal, apresentados na Tabela 11, demonstram resultados positivos. Desta forma, os municípios integrantes do quartil 1 apresentam um nível péssimo de governança municipal. No quartil 2, os municípios apresentam um nível baixo, no quartil 3, um bom nível, e no quartil 4, um alto nível de governança.

Posteriormente, realizou-se o teste de Kolmogorov-Smirnov em cada quartil, para verificar se as variáveis da pesquisa apresentavam distribuição normal. Considerando que os testes rejeitaram a hipótese nula da existência de distribuição normal, realizou-se a estatística descritiva e a correlação de Spearman para verificar a relação entre os níveis de governança municipal e a classificação do rating de crédito, como apresentado na Tabela 12.

Tabela 12. Correlação das variáveis de Governança e Rating por Nível

\begin{tabular}{lllllll}
\hline & \multirow{2}{*}{ Quartis } & & (RAT) & \multicolumn{3}{l}{$\begin{array}{l}\text { Correlação de } \\
\text { Spearman }\end{array}$} \\
\cline { 2 - 7 } & Média & $\begin{array}{l}\text { Desv. } \\
\text { Pad. }\end{array}$ & Média & $\begin{array}{l}\text { Desv. } \\
\text { Pad. }\end{array}$ & Coeficiente & P-valor \\
\hline $\mathrm{Q} 1$ & 0,4011 & 0,0356 & 2,9641 & 0,8565 & $0,190^{* * *}$ & 0,014 \\
\hline $\mathrm{Q} 2$ & 0,4910 & 0,0216 & 3,4731 & 0,7977 & $0,191^{* * *}$ & 0,013 \\
\hline $\mathrm{Q} 3$ & 0,5611 & 0,0189 & 3,4970 & 0,8205 & $0,138^{*}$ & 0,076 \\
\hline $\mathrm{Q} 4$ & 0,6343 & 0,0350 & 3,7083 & 0,6029 & $-0,012$ & 0,880 \\
\hline
\end{tabular}

Fonte: Dados da pesquisa (2018).

GOV = Governança; RAT $=$ Rating; Desv. Pad. = Desvio padrão;

${ }^{* * *}$ significante ao nível de $1 \%,{ }^{* *}$ significante ao nível de $5 \%$ e ${ }^{*}$ significante ao nível de $10 \%$.

Com base na Tabela 12, observa-se que existe uma relação de influência positiva, ao nível de significância de $1 \%$, para aqueles municípios que apresentaram um nível péssimo e baixo de governança. Já para os municípios agrupados no nível bom de governança demonstram a mesma relação, porém, a um nível de $10 \%$ de significância. Neste sentido, pode-se afirmar que a governança municipal impacta positivamente, 
na classificação do rating aplicado ao setor público, nos municípios enquadrados nos níveis mais baixos de governança.

Por outro lado, no nível mais alto de governança, não se pode afirmar de forma significativa, porém, ao observar as médias dos níveis de governança e a classificação do rating de crédito dos municípios, percebe-se que, à medida que aumentam os resultados dos níveis de governança, também há um aumento na classificação do rating.

\section{CONCLUSÕES}

Este artigo fornece uma análise do nível de influência da governança municipal na classificação do rating de crédito. Baseia-se em conceitos de governança corporativa, governança aplicada ao setor público e rating de crédito. Considerações teóricas da relação entre governança e a classificação do rating de crédito corporativo indicam a necessidade de ampliar a pesquisa do tema, com vistas a identificar a relação no setor público.

A hipótese do artigo de que o nível de governança do município impacta positivamente na classificação do rating de crédito aplicado ao setor público não foi rejeitada, corroborando com os achados de outras pesquisas.

A matriz de correlação mostrou indícios de que a governança está associada à classificação do rating de crédito. Ao analisar o conjunto das dimensões que formam a governança, a correlação observada foi de $33,6 \%$, ao nível de significância de $1 \%$. O sinal positivo aponta que os municípios que apresentaram melhores resultados podem apresentar melhores classificações no rating de crédito, ou seja, os municípios que revelam ter boas práticas de governança apresentam uma melhor qualidade de crédito municipal, portanto, um menor risco de ser inadimplente e maior capacidade em tomar crédito.

Em relação à influência, foi confirmado que existe relação significativa e positiva entre o nível de governança municipal e as notas de classificação de rating de crédito. Os resultados evidenciaram poder explicativo e o modelo mostrou-se bem ajustado aos dados, apresentando significância estatística ao nível de 1\%. Demonstra-se, por meio das estimativas positivas, que quanto maior o nível de governança, melhor a classificação do rating de crédito do município. Dessa maneira, o conjunto de boas práticas de governança exerce influência positiva sobre a qualidade do crédito municipal, confirmando os resultados esperados mencionados na literatura aplicada ao setor privado.

Quanto às demais variáveis, verificou-se a seguinte influência: $\mathrm{O}$ município, sendo capital, tende a apresentar maiores classificações no rating de crédito; quanto ao porte, os municípios de até 20.000 habitantes, apresentaram uma associação positiva, enquanto que as demais categorias não apresentaram associação; para as demais variáveis não apresentaram significância estatística. Assim, o recebimento de recursos da União e dos estados e a realização de operações de crédito, não interferem na associação entre o nível de governança municipal e as notas de classificação do rating de crédito.

Nos resultados da relação entre os níveis de governança e a classificação do rating de crédito, indicaram uma maior influência nos menores níveis de governança. Ou seja, os municípios que apresentaram baixos níveis de governança tendem a ter uma melhor classificação de rating de crédito.

Esta pesquisa pode contribuir com os gestores públicos, para que estes se atentem às práticas de governança adotadas, uma vez que estas terão influência na obtenção de empréstimos presentes e futuros, haja vista a relação com o rating de crédito. Ademais, níveis mais altos de governança obterão classificações melhores de rating e assim, capacitarão os municípios a obter a garantia da União, facilitando os empréstimos pretendidos. Diante disso, a possibilidade de obtenção de recursos financeiros poderá possibilitar maiores gastos em políticas públicas, criando efeito multiplicador nos benefícios à população.

O desenvolvimento deste estudo permitiu observar aspectos a serem desenvolvidos em outras pesquisas, com objetivo de expandir o entendimento da classificação do rating de crédito municipal no Brasil. Recomenda-se investigar a relação entre a governança e a classificação do rating de crédito em outros períodos 
e municípios para investigar se os resultados obtidos se assemelham aos desta pesquisa. Analisar a relação adotando a classificação do rating de crédito por meio das metodologias utilizadas nas agências de classificação de ratings e investigar a relação de outras variáveis que possam ter influência, na classificação do rating de crédito municipal.

Por fim, embora não se tenha dúvida de que seja necessário pesquisar mais sobre a governança municipal e classificação do rating de crédito, espera-se que este artigo de enfoque empírico forneça alguns insights críticos sobre o campo da administração pública municipal.

\section{REFERÊNCIAS}

Aman, H., Nguyen, P. (2013). Does good governance matter to debtholders? Evidence from the credit ratings of Japanese firms. Research in International Business and Finance, 29(1), 14-34.

Ashbaugh-Skaife, H., Collins, D. W., LaFond, R. (2006). The effects of corporate governance on firms' credit ratings. Journal of accounting and economics, 42(1), 203-243.

Aziz, M. A. A., Ab Rahman, H., Alam, M. M., Said, J. (2015). Enhancement of the Accountability of Public Sectors through Integrity System, Internal Control System and Leadership Practices: A Review Study. Procedia Economics and Finance, 28, 163-169.

Bairral, M. D. C., Silva, A. H. C. Alves, FJ dos S. (2015). Transparência no setor público: uma análise dos relatórios de gestão anuais de entidades públicas federais no ano de 2010. Revista de Administração Pública, 49(3), 643-675.

Bernardes, M. B., Santos, P. M., Rover, A. J. (2015). Ranking das prefeituras da região Sul do Brasil: uma avaliação a partir de critérios estabelecidos na Lei de Acesso à Informação. Revista de Administração Pública, 49(3), 761-792.

Berthelot, S., Morris, T., Morrill, C. (2010). Corporate governance rating and financial performance: a Canadian study. Corporate Governance: The international journal of business in society, 10(5), 635-646.

Bessis, J. (2011). Risk management in banking. John Wiley \& Sons. London.

Bhojraj, S., Sengupta, P. (2003). Effect of corporate governance on bond ratings and yields: The role of institutional investors and outside directors. The Journal of Business, 76(3), 455-475.

Bolívar, M. P. R., Pérez, C. C., Hernández, A. M. L. (2007). E-Government and Public Financial Reporting The Case of Spanish Regional Governments. The American review of public administration, 37(2), 142-177.

Brito, G., Pimentel, R. C. (2012). Risco nas operações de renda fixa. LIMA, G. ASF; LIMA, IS; PIMENTEL, 183-197.

Brito, G. A. S. A. Assaf, Neto (2008). Modelo de classificação de risco de crédito de empresas. Revista Contabilidade \& Finanças, 19(46), 18-29.

Cavalcante, M. C. N., De Luca, M. M. M. (2013). Controladoria como instrumento de governança no setor público. Revista de Educação e Pesquisa em Contabilidade, 7(1).

CFA - Conselho Federal de Administração (2015). Índice CFA de Governança Municipal. Recuperado de http://c gp.cfa.org.br/indice-cfa-de-governanca-municipal-igm-cfa/

Cruz, C. F., Ferreira, A. S., Silva, L. M., Macedo, M. S. (2012). Transparência da gestão pública municipal: um estudo a partir dos portais eletrônicos dos maiores municípios brasileiros. Revista de Administração Pública, 46(1), 153-76.

Esmark, A. (2009). The functional differentiation of governance: Public governance beyond hierarchy, market and networks. Public Administration, 87(2), 351-370.

Ezzamel, M., Reed, M. (2008). Governance: A code of multiple colours. Human Relations, 61(5), 597-615.

Fávero, L. P., Belfiore, P., Silva, F. L., Chan, B. L. (2009). Análise de dados: modelagem multivariada para tomada de decisões. Rio de Janeiro: Elsevier.

Fukuyama, F. (2013). What is governance?. Governance, 26(3), 347-368.

Gujarati, D. N. (2009). Basic econometrics. Tata McGraw-Hill Education. 
Hwang, J., Akdede, S. H. (2011). The influence of governance on public sector efficiency: A cross-country analysis. The Social Science Journal, 48(4), 735-738.

Hölmstrom, B. (1979). Moral hazard and observability. The Bell journal of economics, 74-91.

IBGC - Instituto Brasileiro de Governança Corporativa. Governança corporativa. Recuperado de http://www.ibgc .org.br

IFAC - International Federation of Accountants. (2001). Study 13 - Corporate governance in the public sector: a governing body perspective. Recuperado de www.ifac.org

Jensen, M. C., Meckling, W.H. (1976). Theory of the firm: Managerial behavior, agency costs and ownership structure. Journal of financial economics, 3(4), 305-360.

Kitagawa, C. H., Godoy, C. R., de Albuquerque, A. A., de Carvalho, F. L. (2007). Estudo empírico sobre o comportamento do custo de capital próprio das empresas listadas nos níveis 1 e 2 de governança corporativa da Bovespa. Rio de Janeiro: Encontro da Associação de Pós-Graduação e Pesquisa em Administração.

Kjaer, A. M. (2004). Governance: key concepts. Cambridge, UK.

Lee, S. C., Lin, C. T. (2010). An accounting-based valuation approach to valuing corporate governance in Taiwan. Journal of Contemporary Accounting \& Economics, 6(2), 47-60.

Leftwich, A. (1994). Governance, the State and the Politics of Development. Development and change, 25(2), 363-386.

Matias-Pereira, J. (2010). A governança corporativa aplicada no setor público brasileiro. Administração Pública e Gestão Social, 2(1), 109-134.

Murcia, F. C. S. (2012). Rating de Crédito no Brasil: fatores determinantes e impacto de anúncios nos preços das ações. Tese de Doutorado em Administração, Universidade Federal de Santa Catarina, Florianópolis, SC, Brasil.

Pereira, P. A. (2009). Politica social: temas \& questôes. Cortez.

Pereira, L. H. M., Martins, O. S. (2015). Rating de crédito, governança corporativa e desempenho das empresas listadas na BM\&FBOVESPA. Revista de Gestão, 22(2), 205-221.

Pires, R. R. C., Gomide, A. D. Á. (2016). Governança e capacidades estatais: uma análise comparativa de programas federais. Revista de sociologia e politica, 24(58), 121-143.

Plattner, M. F. (2013). Reflections on Governance. Journal of Democracy, v. 24, i. 4, p. 17-28. Recuperado de http: $/ /$ muse.jhu.edu/article/523083

Portaria n. 501, de 23 de novembro de 2017. (2017). Confere a Secretaria do Tesouro Nacional a atribuição de calcular a capacidade de pagamento dos Estados, Municípios e do Distrito Federal que pleitearem a concessão de garantia ou aval da União às suas operações de crédito. Brasília. 2017. Recuperado de http://www.fazenda.gov.br/acesso-a-informacao/institucional/legislacao/portarias-ministerial/2017/porta ria-ndeg-501-de-24-de-novembro-de-2017

Rhodes, R. A. W. (1996). The new governance: governing without government. Political studies, 44(4), 652-667.

Rhodes, R. A. W. (1997). Understanding governance: Policy networks, governance, reflexivity and accountability. Open university press.

Secchi, L. (2009). Modelos organizacionais e reformas da administração pública. Revista de Administração Pública, 43(2), 347-369.

Secretaria do Tesouro Nacional. (2017). Nova Metodologia de Capacidade de Pagamento: apresentação completa sobre a nova metodologia/Tesouro Nacional. Brasilia: STN, Secretaria do Tesouro Nacional. Recuperado de ht tp://www.tesouro.fazenda.gov.br/sist

Slomski, V. (2010). Manual de contabilidade pública: um enfoque na contabilidade municipal, de acordo com a Lei de Responsabilidade Fiscal. São Paulo: Atlas.

Silva, E. S., dos Santos, J. F., Almeida, M. A. (2012). Os efeitos dos mecanismos de Governança Corporativa sobre os ratings de crédito das debêntures. Revista de Negócios, 17(3), 80-93.

Soares, G. D. O. G., Coutinho, E. S., de Camargos, M. A. (2012). Determinantes do rating de crédito de companhias brasileiras. Contabilidade Vista \& Revista, 23(3), 109-143. 
Stewart, J., Asha, F., Shulman, A., Ng, C., Subramaniam, N. (2012). Governance disclosure on the Internet: The case of australian state government departments. Australian Journal of Public Administration, 71(4), 440-456.

Subramaniam, N., Stewart, J., Ng, C., Shulman, A. (2013). Understanding corporate governance in the Australian public sector: A social capital approach. Accounting, Auditing \& Accountability Journal, 26(6), 946-977.

Suzart, J. A. S. (2014). As informações contábeis governamentais e as agências de classificação de risco de crédito. Revista de Contabilidade \& Controladoria, 6(3), 108-126.

Tribunal de Contas da União. (2014). Governança Pública: referencial básico de governança aplicável a órgãos e entidades da administração pública e ações indutoras de melhoria/Tribunal de Contas da União. Brasília: TCU, Secretaria de Planejamento, Governança e Gestão. Recuperado de http://portal2.tcu.gov.br/portal/pls/portal/ docs/26 66622.PDF

Torrezan, R. G. A. (2017). Federalismo Fiscal e a desconstrução dos estados: uma análise sob a perspectiva do endividamento público. Dissertação de Mestrado, Faculdade de Ciências e Letras da UNESP, Araraquara, SP, Brasil.

Viana, E. (2010). A governança corporativa no setor público municipal: um estudo sobre a eficácia da implementação dos princípios de governança nos resultados fiscais. Tese de doutorado, Universidade de São Paulo, São Paulo, SP, Brasil.

\section{BY-NC-ND}

